\title{
Development of Influential Factors of Creativity Scale for College Students*
}

\author{
Shutian Deng \\ School of Economics \& Management \\ South China Normal University \\ Guangzhou, China 510006
}

\begin{abstract}
This study is to develop the Influential Factors of Creativity Scale for College Students (IFCSCS), test its validity and reliability, and explore the effective tools for the study. Total 654 college students were selected. All participants were divided into entry port analysis and exploratory factor analysis; according to another sample, 559 people were conducted confirmatory factor analysis. As a result, the developed scale consisted of 18 projects, including 4 factors, the creativity education in school, creative thinking and skills, social creativity atmosphere and creative personality. Totally $61.462 \%$ of the total variance was explained. It had satisfied structure validity. The Cronbach coefficient was 0.911 for the whole scale and 0.755 0.842 for the 4 factors. It can be concluded that the development of influential factors of creativity scale for college students possesses a good validity and reliability, and could be used as a tool to measure the influential factors of creativity for college students.
\end{abstract}

Keywords-college student; creativity; influential factors; validity; reliability; psychometrics

\section{INTRODUCTION}

Innovative ability is an important foundation and guarantee for human beings to understand and transform the world. Everyone has the creative ability, which has become the consensus of educational circles [1]. Innovative ability is a kind of synthetic ability. This view deems that innovative ability is the ability of an individual to use all known information, including existing knowledge and experience, to produce something that is unique, novel, of social or personal value, which is the synthesis and the highest manifestation of all kinds of human abilities [2][3][4][5]. They deem that innovative ability consists of three parts: innovative consciousness, innovative thinking and innovative skills with innovative thinking as its core. Many foreign scholars define innovative ability from its components and systems. Amabile T.M. expresses creativity as the integration of internal motivation, relevant knowledge and competence in the professional field and creativity-related skills, and the interaction of these three components will produce innovative ability [6]. It can be seen that innovative ability is a kind of synthetic ability formed by the interaction of multiple factors, which can produce something that is unique, novel, social or personal value things.

*Fund Project: Research on the Cultivation of College Students' Innovative Ability of the Young Teachers' Scientific Research and Cultivation Fund Project of South China Normal University (15SK08).
From the multi-dimensional perspective, innovative ability is the synthetic performance of all aspects of human quality in the internal and external environment.

Innovative ability is a kind of synthetic ability, which is influenced by multiple factors. It is conducive to analyzing and clarifying the factors that influence the cultivation of college students' innovative ability. The connotation of innovative ability is defined from the above researches, thus we can see that innovative ability is affected by many factors.

The influence of intelligence on ability is also acknowledged by educational circles. IQ (intelligent quotient) and innovative ability are a non-linear relationship, which high IQ is not a sufficient condition for high creativity, but only a necessary condition. [7] It can be seen that intelligence is an important factor affecting innovative ability.

As an important core and evaluation index of innovative ability, thinking is also an important factor affecting innovative ability. Zheng Richang believes that creativity is mainly the ability to diverge thinking [8]. Sun Zeping adds that innovative ability is a dynamically structured ability system with divergent thinking as its core and image thinking and intuitive thinking as its key [9].

The influence of personality on innovative ability is gradually recognized by the educational circles. The most important personality of scientists has the following characteristics: firstly, they resolutely and decisively do not stop the pace of progress; secondly, they bravely and confidently conceive new ideas; thirdly, they tenaciously oppose the trend; fourthly, they dare to challenge the things what most people have idolized [10]. It can be seen that personality also has a far-reaching impact on innovative ability.

The impact of social environment on innovation has been gradually paid attention by researchers. Amabile T.M. points out that social factors such as evaluation, reward and task constraint, social promotion, role models and families, school education, and even social, political and cultural factors can affect innovative ability [6]. Social factors have both positive and negative effects on innovative ability.

School education plays a positive role in the development of human intelligence and ability. As the main channel of cultivating innovative ability, school teaching has a great influence on the formation and development of students' 
innovative ability [12]. The factors affecting college students' innovative ability in campus education environment are summarized into three aspects: humanistic environment, teaching methods and assessment methods [13]. School atmosphere is another factor affecting college students' innovative ability.

The above researches show that the influential factors of innovative ability come from many aspects, including internal and external reasons, natural factors (heredity) and environmental and educational factors. Individuals have created different innovative abilities due to the interaction among them.

\section{OBJECTS AND METHODS}

\section{A. Objects}

In Guangdong universities, 800 questionnaires were distributed by cluster random sampling, of which 672 were recovered and 368 were valid questionnaires; In addition, 379 online questionnaires were distributed by random sampling in various types of universities in Guangdong, of which 286 were valid questionnaires; a total of 1051 questionnaires and 654 valid questionnaires were collected. Among them, there are 226 boys and 423 girls; 305 in rural areas, 329 in towns; 45 in freshmen, 250 in sophomores, 218 in juniors, 121 in senior students; 225 in science and engineering, 422 in macro liberal arts.

\section{B. Scale Establishment}

Firstly, through referring to the pertinent literature on the influential factors of college students' innovative ability such as Cui Hongqiao [14], and mainly referring to the researches of Xin Yali [15] and Liu Qiang [16] to collect a total of 119 topics in various aspects such as the innovative atmosphere involving the school, the creative teaching of teachers, the innovative atmosphere of society, and innovative thinking etc. and 47 topics are obtained through merger and summary.

Secondly, through the establishment of open questionnaires (what factors do you think will affect the innovative ability of college students? What do you think the factors affecting the innovative ability of college students can be summarized?) 39 experts who are selected research the innovative ability, which obtain the reply from 7 teachers, a total of 70 suggestions and summed up 26 topics such as the consideration of a problem from a diversified and multi-layer way and the exploration of the causes of abnormal phenomenon. Thirty-three undergraduates were selected and surveyed with 330 questions, and 79 suggestions were combined and summarized, such as attitude to new things and students' practical ability

Finally, the author interviews three experts from a university, and sorts out 23 specific impact projects, such as traditional education is error correction education, which results in students' lack of initiative to innovate and standardized education and unified requirements result in students' lower innovation.

According to the above collated projects, in order to improve the face validity of the questionnaire establishment and reduce the possible misunderstandings of college students in filling out the questionnaires, which may lead to excessive errors affecting the reliability and validity, this research invites a psychological teacher, a master of psychology, two senior students, three senior students from economics and management major and researchers to organize and analyze the sources of the above various topics. Through merging and sorting out the descriptions with proximity or repetition of meaning, discussing each topic, analyzing whether the sentences are smooth, whether the descriptive contents conform to the characteristics of students' understanding, and whether ambiguity is easy to occur. In order to ensure the readability of each question, reduce the possible errors in answering the questionnaire, the author finally sorts out the project of the 65 questions.

After the data analysis and opinions of 33 people test, such as "changing phrase expression into sentence expression that makes the ones feel like asking him questions on the spot", deleting 7 projects of minor influence and repetition of intention, and sorting out a predicted scale including 53 projects. The scoring method adopts Likert's 5-point scoring method, which let subjects to judge the impact of each description on the innovative ability of college students. According to the degree of impact, they are given a score of 1 (the smallest impact) to 5 (the greatest impact). 1 indicates that there is no impact, 2 is a slight impact, 3 is some impact, 4 is a greater impact, and 5 is the greatest impact.

\section{Statistical Methods}

Descriptive statistics, project analysis and exploratory factor analysis were performed on the samples $(\mathrm{N}=654)$ by adopting SPSS18.0 software, and confirmatory factor analysis was performed on another sample $(\mathrm{N}=559)$ by adopting LSRELS8.70 software. Fitting between data and model was tested to verify the structural validity of the scale.

\section{RESULTS}

\section{A. Project Analysis}

The content validity of the scale can be discussed by evaluating the quantification of the matching degree between the test projects and the constructed definitions. If a test project can score more than $60 \%$ in the measurements, it is considered to have good content validity [17]. According to this standard, only 39 questions (average score 2.598) can be deleted because are fail to meet the requirements.

The correlation coefficient of product and difference between each project score and the total score is taken as the distinguishing index, and the correlation coefficient between each project and the total score of the scale is significant. Except for 52 questions less than 0.3, the other coefficients are ranged from 0.303 to $0.699, \mathrm{P}<0.01$. Consider to abandon 52 projects with coefficient is less than 0.3 from the perspective of simplified scale.

The discriminability index indicates the degree of discrimination in response to different levels of subjects. According to the project analysis method provided by $\mathrm{Wu}$ Minglong [18], the independent T-test of high and low 
grouping is carried out, and it is found that all the topics reach significant level, which shows that each description can very high distinguish high and low scores, and has good discrimination. Thus the topics are not deleted at this stage.

\section{B. Validity}

1) Exploratory factor analysis: Exploratory factor analysis of the project is carried out, $\mathrm{KMO}=0.955$, according to Kaiser (1974), when KMO is more than 0.90 , it is extremely suitable for factor analysis, and above 0.8 is suitable for factor analysis. Exploratory factor analysis of the project is carried out, approximate $\chi^{2}=15605.345, \mathrm{DF}=1275, \mathrm{P}<0.001$, which indicates that there are common factors in cluster correlation, and data show that the sample is suitable for factor analysis.

Exploratory factor analysis uses principal component analytical approach and the principle that Eigenvalues are bigger than 1, and refers to scree plot to extract their common factors. After the initial factor load matrix is obtained by statistics, the maximum variation method (Varimax) is used for orthogonal rotation to obtain the load matrix of the rotation factor. According to the following principles, the structure of influential factors is analyzed and the factor model is determined.

Factor analysis theory recognizes that load degree represents the correlation between project and common factors. The higher the load degree of a project in one factor, the closer the relationship between the project and this factor, and vice versa is much smaller. The research will delete the topics with factor load less than 0.4 in the process of exploration.
If the load degree of a project in two or more factors is relatively high and the load value is close, it can be classified as a factor according to semantics, or can be deleted.

The improper descriptions which are different greatly from the classification of construction validity are attempted to analyze the factors after they are taken out

In case they are concentrated in the same dimension, but the meaning is significantly different from that of other projects, they should be considered deleting.

A factor project less than 3 is given for deletion [18].

If there are many projects in a specific factor, in order to simplify the questionnaire, we consider deleting the lower load, and see if the deletion can explain whether the total variation has improved.

Combining with the dimensional research by researchers on influential innovative ability, it should consider that some factors with low correlation with conception should be cast out.

When the total cumulative soluble variation is not less than $60 \%$, the explanatory variation of each factor is not less than $5 \%$, and the factor project is more than 3 , the dimension construction is fundamentally consistent with the conception. In addition, projects should be additionally cut and added, when the explanatory percentage and dimension are fundamentally stable, the factor exploration is stopped.

According to the above principles, after about 57 exploratory factor analyses, the author repeatedly explores the number of factors of the scale, and deletes the inappropriate questions, which the factor analysis results of 18 projects with four factors were finally obtained. A total of $61.462 \%$ of the total variation was explained, and the factor load of each project was shown in "Table I".

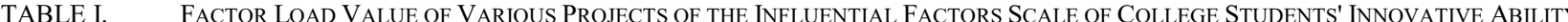

\begin{tabular}{|c|c|c|c|c|c|}
\hline $\begin{array}{l}\text { Original Question } \\
\text { Number }\end{array}$ & Project & $\begin{array}{l}\text { Factor } 1 \\
\text { Load }\end{array}$ & $\begin{array}{l}\text { Factor } 2 \\
\text { Load }\end{array}$ & $\begin{array}{l}\text { Factor } 3 \\
\text { Load }\end{array}$ & $\begin{array}{c}\text { Factor } 4 \\
\text { Load }\end{array}$ \\
\hline Topic 44 & School actively carries out entrepreneurship education & 0.776 & & & \\
\hline Topic 37 & Schools can stimulate students' enthusiasm for innovation & 0.711 & & & \\
\hline Topic 25 & School should establish diversified examination system in schools & 0.654 & & & \\
\hline Topic 38 & Teachers carry out heuristic and participatory teaching & 0.653 & & & \\
\hline Topic 35 & Individuals actively explore the causes of abnormal phenomenon & & 0.752 & & \\
\hline Topic 34 & Individuals have a strong desire to explore & & 0.724 & & \\
\hline Topic 2 & Individuals have rich imagination. & & 0.641 & & \\
\hline Topic 53 & Individuals have strong hands-on ability & & 0.548 & & \\
\hline Topic 28 & Individuals are accustomed to thinking from multiple perspectives & & 0.502 & & \\
\hline Topic 7 & here is an atmosphere for calling for innovation in society & & & 0.795 & \\
\hline Topic 6 & Social atmosphere fully respects individuality & & & 0.789 & \\
\hline Topic 8 & There are more policies to encourage innovation in society. & & & 0.778 & \\
\hline Topic 18 & Innovative achievements can be perfectly protected & & & 0.541 & \\
\hline Topic 13 & $\begin{array}{l}\text { Individuals dare to disagree with authoritative opinions and come up with } \\
\text { own ideas }\end{array}$ & & & & 0.656 \\
\hline \multirow[t]{4}{*}{ Topic 10} & Individuals are full in interest with new things & & & & 0.434 \\
\hline & Characteristic root & 3.158 & 2.88 & 2.796 & 2.229 \\
\hline & Contribution rate $(\%)$ & 17.543 & 16 & 15.535 & 12.384 \\
\hline & Cumulative contribution rate (\%) & 17.543 & 33.543 & 49.078 & 61.462 \\
\hline
\end{tabular}


The results of exploratory factor analysis generally seem to have a higher load of factor and a better uniformity, which is to describe a common quality of influence and meet the expectations of exploration.

Factor 1 consists of five projects, with load ranging from 0.653 to 0.776 , which mainly describes that from the innovative atmosphere, innovative education, examination evaluation, teachers' teaching to consciousness cultivation are all centered on innovative education. They are really weighing the content of the same factor. Therefore, factor 1 is named innovative education in schools.

Factor 2 consists of five projects, with loads ranging from 0.487 to 0.752 and higher load. From the perspective of the project contents, they are the quality of describing individual thinking and ability characteristics. These mainly describe the part of individual intelligence factors, which mainly includes the intellectual factors of innovative thinking and skills, and is named innovative thinking and skills.

Factor 3 consists of four projects with high load, ranging from 0.541 to 0.795 . From the perspective of project contents, these four projects describe the social innovation atmosphere, inclusive personality, encouragement and strength of support for innovation respectively. Therefore, this factor named as the innovative atmosphere of society, which mainly includes innovative policies, measures and social atmosphere in the macro social environment.

Factor 4 consists of four projects, with loads ranging from 0.656 to 0.794 and lower load on other factors, which reflects the multivariate of individual risk, criticism, interest features and value pursuit that is in accordance with the description of creative personality traits. Therefore, this factor is named creative personality.

2) Confirmatory factor analysis: Confirmatory factor analysis $(\mathrm{N}=559)$ was performed on the scale of 18 projects, with results being $\chi^{2}=638.61, \mathrm{df}=129, \chi^{2} / \mathrm{df}=$ $4.950, \mathrm{CFI}=0.94, \mathrm{NNFI}=0.93, \mathrm{RMSEA}=0.087, \mathrm{SRMR}=$ 0.064 . The ratio of $\chi^{2}$ to DF is 4.950 , and the model is acceptable when the ratio is between 2.0 and 5.0, but the index is susceptible to the influence of sample size [19].

The index of Root Mean Square Error of Approximation (RMSEA) is 0.087. The scholar Sterger (1990) pointed out that an RMSEA of less than 0.1 indicates an excellent fit, and that an RMSEA of less than 0.05 is a very good fit [19]. The SRMR of approximate error index (Standardized Root Mean Square Residual) is 0.064, and $\mathrm{Hu}$ and Bentler (1998) considered that less than 0.08 is considered the model is acceptable [19]. The comparative fit index NNFI (Non-Fit Index) is equal to 0.93 , and the comparative fit index CFI (Comparative Fit Index) is equal to 0.94 . The relative fit index ranges from 0 to 1 , and the more the closer to 1 , the more the better. The relative fit index has a 0.9 norm that exceeds 0.9 and the model is acceptable, which is widely used [19]. Based on the above indexes, the four-factor model of the influential factors of college students is well matched and the model is validated, indicating that the scale structure has good validity and meets the requirements of the psychological scale.

\section{Reliability}

The commonly used reliability of internal consistency is adopted and Cronbach $\alpha$ coefficient is adopted to test the reliability. The reliability of $a$ coefficient of the total scale is 0.911 , which shows that the 18 projects are stable in measurement. The coefficient $a$ of the four factors is ranged from 0.755 to 0.842 , and the reliability coefficient is higher. If the reliability coefficient of the total scale is better than 0.8 and the reliability coefficient of the sub-scale is better than 0.7 [18], which shows that the scale has good reliability of scale homogeneity and meets the general requirements of psychometrics.

\section{DISCUSSION}

From the perspective of content validity to analyze, firstly, the data that influences the projects are collected beginning from the open questionnaire that influences the innovative ability of college students, through written interviews with experts, personal interviews and the results of scholars' researches on the influential factors of innovative ability,. Secondly, through content analysis, semantic analysis and small sample test, a pre-test questionnaire with 53 projects was established. Thirdly, using a higher standard, the author carries out project analysis for the questionnaire, and obtains the structure of 18 projects with four factors of influential factors for college students through exploratory analysis. In addition to referring to a large number of relevant research and scale materials, and content analysis, University students, graduate students and university teachers are invited to give advisory opinions. At the exploratory factor analysis stage, we adopt strict standard (such as factor $l o a d \geq 0.4$, factor project number $\geq 4$, the number of variation of single factor explanation $\geq 5 \%$ etc. to explore the influential factors in order to improve the reliability and validity of the established questionnaire,, which can basically ensure that the structural model influenced by four factors has certain content validity.

From the perspective of structural validity, the initial scale factor load (0.434-0.795) and cumulative contribution rate obtained( $61.462 \%$ total variation of explanation) after the exploratory factor analysis of questionnaire are relatively high. The classical factor analysis theory thinks that if there is a moderate correlation between the factors and so there is a high degree of correlation between the factors and the total scale, the measurement can be considered to have structural validity, which can ensure that there are differences between the factors and measures the same psychological characteristics. The correlation between the four factors is between 0.468 and 0.625 that belongs to moderate correlation, which proves that the four factors are interrelated and independent among one another; while the correlation between the factors and the whole is between 0.761 and 0.844 , which has a high degree of correlation. It can be seen that the dimensional structure of influential factors of college students' innovative ability is reasonable and has certain structural validity to a certain extent. 
The internal consistency reliability of the scale meets the requirements of the psychological scale. The reliability test is carried out again with the validation data of the formal scale. The coefficient $\alpha$ of the total scale is 0.892 , and the coefficient $\alpha$ of the sub-scale is $0.695-0.808$. The coefficient reliability of the total scale and sub-scale of the test results has reached the summary requirement of the researcher $\mathrm{Wu}$ Minglong [18]. It shows that the scale of four factors of influential of college students' innovative ability has good reliability.

\section{FUTURE RESEARCH DIRECTIONS}

This research only selects the students who are from a province, and the sample has certain limitations. In the future, the research can test the reliability and validity of the scale in other regions and other groups, and carry out follow-up research. Future research should also focus on the exploration of how these factors influence the degree and mechanism of image cultivation of innovative ability.

\section{CONCLUSION}

Through tests, it is concluded that the scale of factors having influence on college students' innovative ability formulated in this paper has good effect and reliability, and could be used as a tool to measure the influential factors of creativity for college students.

\section{REFERENCES}

[1] (United States) Editor-in-chief of Robert J. Sternberg, Translated by Shi Jiannong, etc. Creativity Manual. [M]. Beijing Institute of Technology Press, 2005.

[2] Zhang Baochen. Reform of Higher Normal Education and Cultivation of Students' Innovative Ability [J]. Educational Theory and Practice, 2004, 04: 40-42. (in Chinese)

[3] Li Yan. On the Cultivation of College Students Innovative Ability [J]. School Party Construction and Ideological Education, 2005, 12: 7576. (in Chinese)

[4] Zhang Peng, Yu Lan, Liu Zhubai, Zhang Yanyan. Research on the Current Situation and Countermeasures of College Students' Innovative Ability Cultivation [J]. University Education Science, 2005, 03:50-53. (in Chinese)

[5] Lu Genshu, Wu Junhua, Zhang Xiaolei. Review of Research on Innovative Ability Evaluation [J]. Higher Education Research, 2008, 06: 50-56. (in Chinese)

[6] Amabile,T.M.The Social Psychology of Creativity. New York: Spingerr-Verlag, 1983:159-185.

[7] Cui Jinggui. Psychological Science and School Innovative Education [J]. Shanghai Education and Scientific Research, 2001, 04: 28-30. (in Chinese)

[8] Zheng Richang. Measurement of Creativity [J]. Psychological Development and Education, 1985, 01: 36-39. (in Chinese)

[9] Sun Zeping. The Ability System of Innovative Education [J]. Education Exploration, 2003, 04: 12-13. (in Chinese)

[10] Yu Guoliang. On Personality and Creativity [J]. Journal of Beijing Normal University (Social Science Edition), 1996, 04: 83-89. (in Chinese)

[11] Zhang Qinglin, Sternberg, R.J. etc. Creative Research Handbook. Chengdu: Sichuan Education Press, 2002: 4-5, 362-371. (in Chinese)

[12] Yao Yuhuan. Teaching Factors and Reform Paths Restricting the Development of College Students' Innovative Ability [J]. China Higher Education, 2008, 08: 28-29+44. (in Chinese)
[13] Li Xicheng, Wang Fayuan. Analysis on the Reform of the College Students' Innovative Ability Training Mechanism of Economy Major. [J], Educational Theory. 2010(04).171-172. (in Chinese)

[14] Cui Hongqiao, Liu Wenchao, Wang Hong. Empirical Study on the Influential Factors of the Cultivation of College Students Innovative Ability of Business Administration Specialty [J]. Journal of Southwest China Normal University (Natural Science), 2013, 02: 160-164. (in Chinese)

[15] Xin Yali. Investigation and Research on the Influential Factors of College Students' Innovative Ability [J]. Psychological Science, 2003, 05: 926-927+950. (in Chinese)

[16] Liu Qiang. Research on the Current Situation of Students' Innovative Ability and Its Influential Factors - Based on the Analysis of Relevant Data of the "Research on the Development of Students in Capital Universities" in 2010[J]. Educational Theory and Practice, 2012, 01:29-32. (in Chinese)

[17] Chen Xiaoping, Xu Shuying, Fan Jingli. Empirical approach of Organization and Management Research. Beijing: Peking University Press. 2008 (in Chinese)

[18] Wu Minglong. SPSS statistical application practice - questionnaire analysis and application statistics. The first edition. Beijing: Science Press. 2003. (in Chinese)

[19] Written by Hou Jietai, Wen Zhonglin, Cheng Zijuan. Structura equation model and its application. The first edition. Beijing: Education Science Press (in Chinese) 